\title{
Gender impact of chasing dirty money policies: A Fantasy Pitch
}

\author{
Bao Hoang Nguyen ${ }^{\mathrm{a}, 1}$ and Jia Chen ${ }^{\mathrm{a}}$ \\ ${ }^{a}$ The University of Queensland, Australia
}

\begin{abstract}
This paper describes the use of the fantasy research pitching exercise in the context of the UQ Summer Research Program. The authors provide their personal reflections on the process of doing the exercise and highlight the role of Faff's $(2015,2017)$ pitching research template as a useful research learning tool.
\end{abstract}

Keywords: Pitching Research, Fantasy Pitching, Gender, Dirty Money

\section{JEL codes: J16; K42}

\section{Introduction}

This research letter provides an example of a fantasy research pitching exercise undertaken, as a team, by two UQ Summer Research Scholars - Jia Chen and Bao Hoang Nguyen. Jia is currently an undergraduate student majoring in Accounting and Bao is a master by course work student majoring in Economics and Finance at The University of Queensland. We are both eager young scholars who have a good academic background, full of enthusiasm to do research but struggling to find the way to kick off our research journey. Fortunately, we got an invaluable opportunity to overcome our "starting-research" challenge by participating in the research project namely "i-TEMPLATE" ${ }^{1}$ offered by Prof. Faff in the UQ Summer Research Program 2016-72. Over a 10-week period starting from late November 2016, under the prudent guidance of Prof. Faff, we experienced a well-designed research program, based on a framework constructed around Faff's $(2015,2017)$ pitching research template - a

\footnotetext{
${ }^{1}$ Corresponding author: The University of Queensland; St Lucia, QLD 4067, Australia; Tel. (+61) 458878 962, E-mail address: bao.nguyen3@uq.net.au, angeljiajia88@gmail.com
} 
succinct and methodical approach to convey a new research idea to an academic mentor. The program is designed to lead us through three stages of using the pitching research template (from the lowest to the highest level of difficulty): Stage 1 Gaining familiarity with the pitching research template and doing a reverseengineering exercise on an existing academic paper; Stage 2 - Developing a "fantasy" pitch on a fictitious topic, and Stage 3-Developing a "real" pitch on our own academic topic. This pitching research letter reflects our work during the second stage of the program.

The remainder of this pitching research letter is organized as follows. In section 2, we provide a brief commentary on the fantasy pitch exercise. In section 3 , we offer our personal reflections on doing the exercise, while section 4 concludes.

\section{Brief commentary on the fantasy pitch exercise}

The fantasy pitch exercise was initially road tested in a PhD course at the UQ Business School, basing on Faff's $(2015,2017)$ pitching research template. The exercise was designed to allow $\mathrm{PhD}$ students to explore the fundamental principle of the pitching research tool under a low stress setting in which the pitching research template was used to pitch a fictitious/nonsense topic (Faff et al., 2016; Faff et al., 2016).

We, as one of three paired teams of six UQ Summer Research Scholars, had the opportunity to experience a similar exercise as described above but within a different context. Relevant to our context, the fantasy pitch exercise served as a turning point to drive us to a higher level of using the pitching research template. At the lower level, with the purpose of being familiar with the pitching research concept, we had been paired up as a team based on our common research interest to do a "reverse engineering" ["RE"] pitch "sparring" exercise. To be more specific, as documented in Faff et al. (2017) - the paper provides a narrative review of this "RE" pitch "sparring" exercise. In our team, we collaboratively populated all items of the template for Zhong et al. (2014). Accordingly, in the fantasy pitch task, we were advised to use the knowledge that we had acquired from the "RE" pitch exercise on Zhong et al. (2014), combined with one of the three topics suggested by Prof. Faff to generate a new angle for our fantasy pitch.

Regarding the process of choosing the topic for the fantasy pitch, we were provided with a range of articles linked to the recent issues of "dirty money", "cashless society", and "digital currency" (see Anand, 2016; Barboza, 2013; Bearup, 2016; Eyers, 2016; Frost, 2016; Gupta, 2016; Lewis, 2016; Malpass, 2016; Malpas \& Muligan, 2016). With the lens borrowing from Zhong et al. (2014), we proposed that it would be a new approach to consider the potential social impact of recent Indian government policy to withdraw maximum denomination bank notes described in 
Anand's (2016) article - "Indians rush frantically to launder their black money" were analyzed according to gender. Therefore, we decided to explore gender difference as a new perspective on the "dirty money" topic. The novelty of our approach is reflected in the following Mickey Mouse diagram (Figure 1)

Figure 1. Mickey Mouse diagram characterizing novelty of research idea.

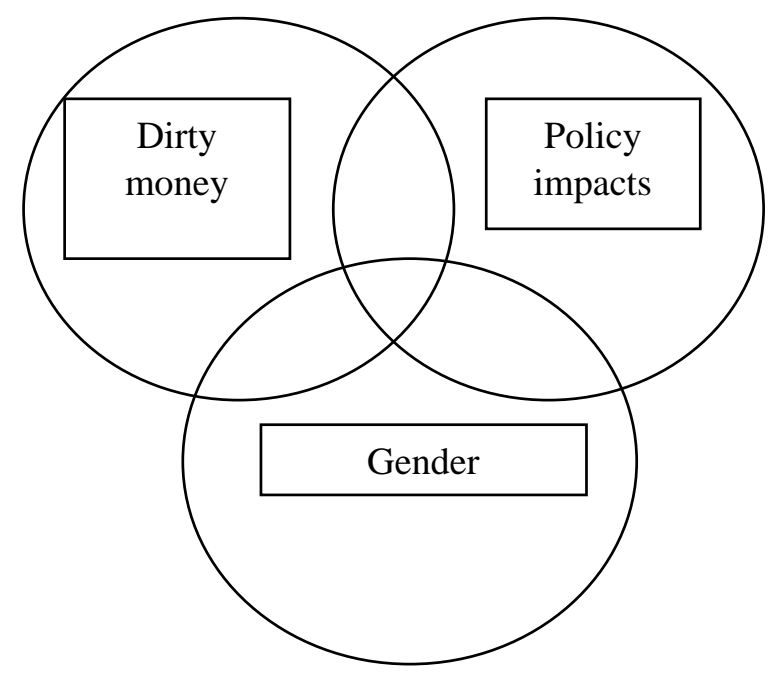

After a few meetings and discussion, we came up with the pitch working title of "Chasing dirty money: does gender matter?" as shown in Table 1.

\section{Personal reflections of the Fantasy pitch exercise}

In the process of preparing our fantasy pitch, we found it requires a great effort of collaboration to populate the item (B) Basic Research Question because we individually approached the topic from two different perspectives. While Bao chose to analyze the ways in which different genders react to the policy, Jia preferred investigating the different impacts the policy caused on different genders. This difference in approach provided us a great opportunity to discuss and consider the "pros" and "cons" and other aspects of the research proposal. After discussion, we agreed that the approach proposed by Jia might be easier for us to (hypothetically) collect data through undertaking a questionnaire survey. Therefore, we decided to set up the research question as: Does chasing dirty money activities affect males and females differently? Though we realized that it would be a bit tricky to put gender and chasing dirty money together, we were confident that our research question would be suitable and original after discussion. 
Another challenge we met was how to fill in item (C) Key paper(s). Due to the time constraint in the first meeting, we just used the key word "dirty money" to search in Google Scholar and found two papers with titles that seemed to be relevant to our topic. However, we knew that we need to scan more literature in choosing the most suitable key paper (even though this is a fantasy exercise). At the latter stage of doing the fantasy pitch exercise, we carefully revised the "key papers" item and realized that one of our originally chosen papers no longer seems so relevant to our research topic. Moreover, we supposed that it would be better if a paper focusing on gender impact of economic policy is included in our fantasy pitch. Therefore, we did another Google Scholar search with the key word "gender impact of policy" and luckily we found Himmelweit (2002), which provided support to our research proposal of looking at the gender aspect of chasing dirty money policies.

The process of filling in the "3-2-1" part once again highlighted the advantage of teamwork in our fantasy pitch task. To prepare for the second meeting, we decided to complete the whole template individually and then discuss to arrive at a consensus. Regarding Bao's own process to populate the template, Bao found it quite difficult to go into detail in each template item, especially the three core aspects because "dirty money", "gender" and the questionnaire method are all new areas to him. Thus, he found that in his individual work, the "3-2-1" part was quite general and vague. Similarly, Jia felt a bit lost when she was generating the key item "idea" of the pitch. After scanning the literature for a long time online, she doubted the feasibility of the research herself again and again due to limited resources, but luckily, her efforts did pay off. Specifically, she found a kind of book related to chasing dirty money activities. In that book there was a classification of the governments' main activities to chase dirty money in the US. She felt it would be valuable to focus on two main common activities that governments around the world have pursued, namely, "withdrawing maximum banking notes" and "setting up anti money laundering regimes". Also she thought that this research could provide assistance to policy makers in decision making as well. At our meeting, Bao agreed with Angel's idea and we strived to revise and combine our individual work into an improved final version. We made great progress and both of us realized that the fantasy contribution of our study might be more obvious when viewed from a policy maker perspective, and the first hand data we proposed to collect from questionnaires mailing to respondents would be original. It is important to point out that we were very clear in mind the aim of fantasy pitching, and therefore we did not focus too much on how the questionnaire should be designed in detail.

Overall, our fantasy pitch was completed in "non-linear" manner. After populating all items, we came back and enhanced the weak parts of our template. The most significant improvement was made to the "ideas" item in which we formed an oneway main hypothesis stating the unintended influences of withdrawing maximum banking notes and anti-money laundering activities on females are more significant than on males. 


\section{Conclusion}

This letter outlines our fantasy research pitch exercise on the topic of "dirty money" in the context of i-TEMPLATES project - the UQ Summer Research Program. This exercise provided us a better understanding of Faff's $(2015,2017)$ pitching research template and helped us to apply the template more practically. We found that after successfully completing the fantasy pitch task, we became more confident about using the pitching research tool in developing our own "real" research proposal.

\section{References}

Anand, G. (2016) "Indians Rush Frantically to Launder their Black Money", The Australian Financial Review, 24 November, 2016, available online at www.afr.com

Barboza, D. (2013) "Chinese Run their Economy on Bales of Old-fashioned Cash", International Herald Tribune, Global Edition of New York Times, 2 May, 2013

Bearup, G. (2016) "Modi Pulls the Rug out from under the Feet of Shonks and Criminals", The Australian Newspaper, 14 November, 2016

Eyers, J. (2016) "Central Banks Look to the Future of Money with Blockchain Technology Trial”, The Australian Financial Review, 21 November, 2016, available online at www.afr.com

Faff, R. (2015) “A Simple Template for Pitching Research", Accounting and Finance, vol. 55, no. 2: 311- 336

Faff, R. (2017) "Pitching Research", Available at SSRN: http://ssrn.com/abstract=2462059 or http://dx.doi.org/10.2139/ssrn. 2462059

Faff, R., Ali, S., Atif, M., Brenner, M., Chowdhury, H., Crudas, L., Joubet, A., Malik, I., Nagar, V., Mi, L., Pullen, T., Siegrist, M., Smythe, S., Stephenson, J., Zhang, B. \& Zhang, K. (2016) "Fantasy Pitching", Available at SSRN: http://ssrn.com/abstract $=2782778$ or http://dx.doi.org/10.2139/ssrn.2782778

Faff, R., Carrick, R., Chen, A., Escobar, M., Khong, B. X. M., Nguyen, B. H. \& Tunny, W. (2017) "Pitching Research: A Reverse-Engineer "Sparring" Experiment with UQ Summer Research Scholars", Available at SSRN: https://ssrn.com/abstract=2903811

Faff, R., Wallin, A., Brosnan, M., Carrillo, N., Darmawan, D., Dorris, A., Groen, M., Listiani, N., Maxwell, V., Orole, F., Pham, A., Salehudin, I., Simons, M., To, D., Tsoi, J., Wong, C., Woods, K., Yossa, N. \& Zhaunerchyk, K. (2016) "Fantasy Pitching II: Star Wars vs. Pokemon vs. R\&D vs. Uber", Available at SSRN: http://ssrn.com/abstract=2827425 
Frost, J. (2016) "No End to the War on Dirty Money Says the Man Who Conned Pablo Escobar", The Australian Financial Review, 11 December, 2016

Gupta, G., (2016), "Venezuela Yanks 50pc of banknotes in circulation as it tries to Fight Inflation", The Australian Financial Review, 12 December, 2016

Himmelweit, S. (2002) "Making visible the hidden economy: The case for gender-impact analysis of economic policy", Feminist Economics, vol. 8, no.1: 49-70

Lewis, R. (2016) "Task Avoidance Taskforce to Weigh Future of \$100 Note, Black Economy", The Australian Newspaper, 14 December, 2016

Masciandaro, D. (1999) "Money laundering: the economics of regulation", European Journal of Law and Economics, vol. 7, no. 3: 225-240

Malpass, L. (2016) "Narendra Modi's Demonetisation Hits Gold and Diamond Merchants", The Australian Financial Review, 18 November, 2016

Malpass, L. \& Muligan, M. (2016) "Indians Back Modi's Harsh Medicine", The Australian Financial Review, 16 November, 2016

Zhong, T., Faff, R., Hodgson, A. \& Yao L. J. (2014) "The role of board gender on the profitability of insider trading", International Journal of Accounting \& Information Management, vol. 22, no.3: 180 - 193 
Table 1. Completed 2-page fantasy pitch template on the topic of "gender impact of chasing dirty money policies"

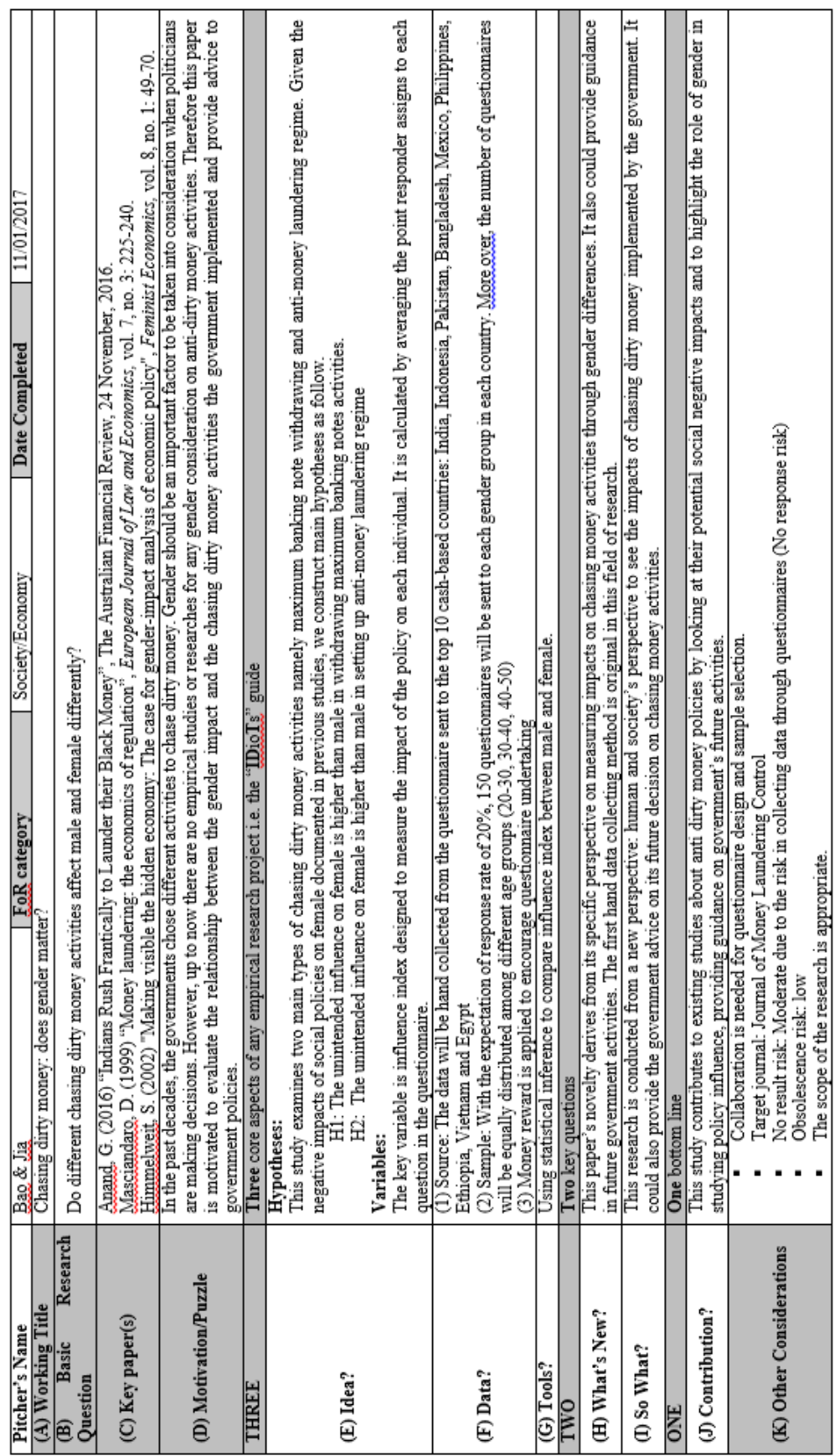

Vol. 16, No. 4 
1 "i-TEMPLATES": innovation in Teaching and Enhanced Mentoring of Pitch Learning Across Tertiary Education Spectra.

${ }^{2}$ The Summer Research Scholar Program at the University of Queensland aims at providing UQ students (both undergraduate and coursework Masters) with an opportunity to gain research experience. Successful candidates are able to extend their knowledge of an area of interest and develop analytical, critical thinking, and communication skills. The UQ Summer Research Programs are administered by the UQ Advantage Office, via the Student Engagement Team. For more details, visit the UQ Advantage Office website:

http://www.uq.edu.au/uqadvantage/undergraduate-research-programs. 